\title{
Adaptación al cambio climático y gestión de riesgos naturales: buscando síntesis en la planificación urbana ${ }^{1}$
}

\author{
Jonathan R. Barton² y Felipe Irarrázaval ${ }^{3}$
}

\begin{abstract}
RESUMEN
Desde fines de la década de 1980, ha surgido un vocabulario nuevo para acompañar las preocupaciones con el cambio climático. Sin embargo, este artículo argumenta que los conceptos utilizados en términos de adaptación urbana forman parte de la historia de la planificación urbana. Es por eso que es necesario entender el cambio climático no como un fenómeno nuevo y que no debe ser desconectado de esta historia. A través de una discusión conceptual contextualizada históricamente desde 1970 y con una revisión de los instrumentos de planificación urbana en materia de cambio climático en Chile, el artículo plantea que el cambio climático ha sido central en la planificación urbana y que el énfasis sobre cambio climático no es más que una reafirmación de este énfasis que construye sobre el concepto de 'riesgos urbanos'. Concluye que un enfoque integral y históricamente contextualizado de riesgo urbano debe formar la base para la respuesta esperada en torno de la Política Nacional de Adaptación al Cambio Climático (2014) en conjunto con la Política Nacional de Desarrollo Urbano (2014).
\end{abstract}

Palabras clave: Cambio climático, adaptación, riesgos urbanos, planificación urbana, comunidades epistémicas.

\begin{abstract}
Since the late 1980s, a new vocabulary associated with concerns about climate change has emerged. Nevertheless, this article argues that the concepts used to describe urban adaptation are a part of the history of urban planning. Consequently, climate change should not be seen as a new phenomenon disconnected from this past. By means of a historically contextualized conceptual discussion and a review of urban planning instruments used to address climate change in Chile, the article argues that climate change has been central to urban planning and that the emphasis on climate change is no more than a reaffirmation of this connection built on the concept of 'urban risk'. It concludes that an integrated and historically contextualized approach based on urban risk should form the basis to the response within the framework of the National Climate Change Adaptation Policy (2014) in conjunction with the National Urban Development Policy (2014).
\end{abstract}

Key words: Climate change, adaptation, urban risk, urban planning, epistemic communities

1 CEDEUS (Conicyt/Fondap/15110020). Artículo recibido el 1 de junio de 2015, aceptado el 11 de septiembre de 2015 y corregido el 31 de diciembre de 2015.

\footnotetext{
2 CEDEUS (Conicyt/Fondap/15110020). Instituto de Estudios Urbanos y Territoriales, Pontificia Universidad Católica de Chile (Chile). E-mail: jbarton@uc.cl

3 CEDEUS (Conicyt/Fondap/15110020) (Chile).

E-mail: firarrazava@uc.cl
} 
Hay consenso que el cambio climático va a redefinir cómo vivimos en las ciudades. Eventos extremos recientes, tales como los huracanes Sandy y Katrina en EE.UU., las inundaciones del 2013 en Europa central, el aluvión de Salgar en Colombia, los aluviones en Río de Janeiro el 2010, la escasez hídrica en diversos territorios, las nuevas geografías de vectores y enfermedades, y las migraciones de "refugiados climáticos", entre muchas otras experiencias, sugieren transformaciones importantes para el siglo XXI. Si bien el cambio climático entrega un nuevo contexto, que define en gran medida los procesos de desarrollo urbano, parte de sus impactos específicos no son del todo nuevos para las ciudades. Ejemplo de esto son los riesgos naturales, los cuales si bien adquieren una connotación distinta en el marco del cambio climático, lo anteceden considerablemente en términos históricos.

El presente artículo argumenta que el cambio climático requiere de cambios sustanciales para generar procesos de adaptación, no obstante estos deben ser erguidos sobre las experiencias previas, y los riesgos naturales hidrometeorológicos son ejemplo de eso en Chile. Sin embargo, el análisis de estas experiencias debe ser crítico, en tanto se requieren modificaciones estructurales en materia de cambio climático. Esto se contextualiza en el argumento de Pelling (2011), respecto a que la adaptación al cambio climático debe partir de una revisión crítica de las estructuras existentes para tener en consideración las experiencias previas, más que reinventar la rueda con nuevos términos que en su raíz no son del todo nuevos, y ofuscan la posibilidad de analizar críticamente las estructuras sociales (Schipper \& Pelling, 2006; Pelling, 2011).

El artículo tiene dos cuerpos principales. El primero es un análisis posestructural del concepto de 'riesgo urbano' y las formas en las cuales se han construido comunidades epistémicas en torno de ideas de adaptación desde tres campos de conocimiento: planificación urbana, gestión de riesgos y adaptación al cambio climático. Se emplea la noción de genealogías, usado por Foucault (1994) para la evolución de estas comunidades. El análisis se basa en la historia de la construcción de estas comunidades, y en particular durante las últimas décadas debido a que en este surgen con fuerza los campos de gestión de riesgo y adaptación al cambio climático. Establece como estos silos de conocimiento fueron construidos bajo una lógica modernista, con una falta de apertura hacia otros campos. También indica cómo, en años recientes, está aumentando la permeabilidad entre estas comunidades debido a la transversalidad de los riesgos urbanos contemporáneos y los desafíos para los tomadores de decisiones locales. El informe especial de la IPCC (2012) sobre riesgos y adaptación marca un hito en este aspecto, y abre espacio para una nueva construcción conceptual capaz de integrar elementos socioecológicos urbanos de forma holística.

El segundo cuerpo del artículo aterriza el primer apartado en base a la experiencia en Chile en materia de gestión de riesgos naturales urbanos y adaptación al cambio climático.

Se aborda la experiencia en materia de riesgos naturales de tipo hidrometeorológico, fundamentalmente cómo esta se ha materializado en aspectos normativos de planificación urbana, y cómo se han absorbido elementos de la discusión del cambio climático. En específico son abordados los planes reguladores de las cinco ciudades más pobladas de Chile al año 2002, y su relación con elementos que surgen del debate de cambio climático, en particular respecto a procesos de adaptación y gestión de riesgos naturales: Área Metropolitana de Santiago, Área Metropolitana de Valparaíso, Área Metropolitana de Concepción, Coquimbo-La Serena, y Antofagasta. Estas ciudades además de tener una importante representatividad demográfica a nivel nacional, también son las que más frecuentemente son afectadas por eventos hidrometeorológicos críticos, lo cual re afirma la relevancia de considerar su experiencia (pese a lo negativa que pueda ser). Se trabaja solamente con este tipo de eventos porque en el contexto de los riesgos naturales asociados al cambio climático para Chile, son los que se encuentran más asociados a eventos críticos. Complementario a lo anterior, se revisan los planes nacionales de adaptación al cambio climático, y se argumenta que estos no contienen elementos nuevos en materia de riesgos urbanos. 
La metodología empleada en el presente trabajo se basa en el análisis documental de dos tipos de fuentes. Se revisó la prensa para identificar eventos hidrometeorológicos críticos en las ciudades, buscando sintetizar estos eventos y dar cuenta de que en la historia reciente de las ciudades chilenas hay una vasta experiencia en materia de desastres naturales de tipo hidrometeorológico. Por otro, se revisan los instrumentos legales asociados a riesgos naturales en materia de planificación urbana, así como también son revisados los planes de adaptación al cambio climático y en menor medida el plan regional de ordenamiento territorial. A estos documentos se les realiza un análisis de contenido, basado en identificar como conceptualizan los riesgos naturales.

\section{Genealogías y comunidades epistémicas de riesgos, planificación urbana y cambio climático}

Foucault (1977) desarrolla el concepto de genealogías para entender la construcción de conocimiento, y supuestas verdades, sobre distintos temas e instituciones. En vez de historias lineales que buscan explicar la fuente de algo en particular y su asociación con una perspectiva o ideología, el uso de genealogías en forma pos estructural facilita una lectura más amplia y dinámica. Como indica Foucault (1977: 139), una genealogía; “...debe registrar la singularidad de los eventos fuera de cualquier finalidad monótona de estos..." ${ }^{4}$.

Por lo tanto, plantea que la historia de las ciencias sociales se basa en la formación de epistemes -sistemas de pensamiento y conocimiento- que postulan ciertas construcciones o "verdades" sobre la experiencia humana (Foucault, 1994). Esto es de particular utilidad para discutir la formación de comunidades epistémicas donde diversos conocimientos son organizados en silos, entre ciertos enfoques disciplinares o perspectivas definidas. Es precisamente la forma de construir el conocimiento bajo una epistemología acordada que une el grupo, y con la cual

4 Traducción de los autores. construye la comunidad que se autoperpetúa como tal. Lo importante de estas comunidades, y siguiendo a Foucault, es que construyen ciertas "verdades" a través de este conocimiento que a la vez es aprovechado para demarcar posiciones de poder. Por ejemplo, la construcción del "problema climático" por científicos y el público general depende no solamente de la ciencia sino de su "framing" o forma de presentación, así como también a los debates políticos asociados con la gestión de riesgos, consenso político y público, e inferencias de la justicia social (ver Giddens, 2008; Wynne, 2010).

\section{Traslapes entre planificación, riesgo urbano y cambio climático}

El conocimiento evoluciona a través de traslapes y momentos claves donde hay avances, o más bien interpretaciones distintas de "la realidad". Según Foucault, no significa progreso según una concepción de modernidad, sino una serie de cambios derivados de que no hay un desarrollo lineal. Es precisamente ese punto en donde este trabajo se centra, en los intersticios en donde se traslapan la planificación del desarrollo, la gestión de riesgos naturales y la adaptación al cambio climático. El argumento de fondo es que la historia de la planificación urbana es una historia de anticipación y gestión de riesgos, así como implica la planificación de desarrollo en el contexto urbano, donde el desarrollo es un concepto en constante reinterpretación: el fin último 'construido' de la interacción de diversos procesos en forma panárquica (necesidades básicas, aumento de ingresos y empleo, infraestructura y edificación, sustentabilidad, reducción de pobreza, bienestar, entre otros) (Gunderson \& Holling, 2002). En vez de construir la planificación urbana como una construcción moderna -surgida con Ebenezer Howard a fines del siglo XIX y con la evolución del movimiento de "town and country planning", seguido por Henri Lefebvre, Jane Jacobs, John Friedmann, Manuel Castells y otros- se debe entender la planificación del desarrollo urbano como un proceso inseparable de la evolución de asentamientos humanos: uno es el espejo del otro, su sine qua non.

Aportes centrales para esto en la planificación urbana, y vinculándola con los riesgos 
naturales son los trabajos de Wisner et al. (2003) y Beck (1992). Mientras imperaba, bajo el pensamiento dominante de la modernidad de gran parte del siglo XX, la idea que el progreso disminuía los diversos riesgos de la vida urbana, Beck enfatizaba el rol del "progreso" en la construcción de nuevos riesgos, manufacturados por la propia innovación. En vez de una lectura que la entelequia de los seres humanos es capaz de reducir los impactos de los riesgos naturales, Beck escribía sobre la capacidad de generar nuevos riesgos, asociados con nuevos medios de transporte, energía nuclear, producción química, etc.; claramente, el cambio climático es el más dramático de esos riesgos. Richard Norgaard (1994) apunta a lo mismo a través de su concepto de "codesarrollo", donde "la naturaleza" se adapta en relación a las adaptaciones humanas, y viceversa, generando un escenario fluido y con alta incertidumbre. Las ideas de Beck y Norgaard han sido muy relevantes para enfatizar las interrelaciones de sistemas socioecológicos, que se ve en forma clara en centros urbanos en términos de su relación con sus entornos (McHale, 2015). Las dimensiones de riesgo forman una parte importante de estos sistemas, en términos de sus procesos -según Gallopin (2003)- de adaptación y flexibilidad, disponibilidad de recursos y homeostasis. Wisner et al. (2003) identifican estas relaciones a través de la siguiente figura (ver Figura $N^{0} 1$ ), que construye los aspectos sociales de los desastres, a la vez desmitifican que la noción que los riesgos naturales son separados de los procesos sociales. Siguiendo esta lógica, los riesgos deben ser entendidos como procesos con aspectos naturales y sociales, lo cual se ve claramente en la evaluación SREX (2012) del IPCC, y en la definición misma de cambio climático.

Figura $\mathrm{N}^{0} 1$

La causalidad social de los desastres

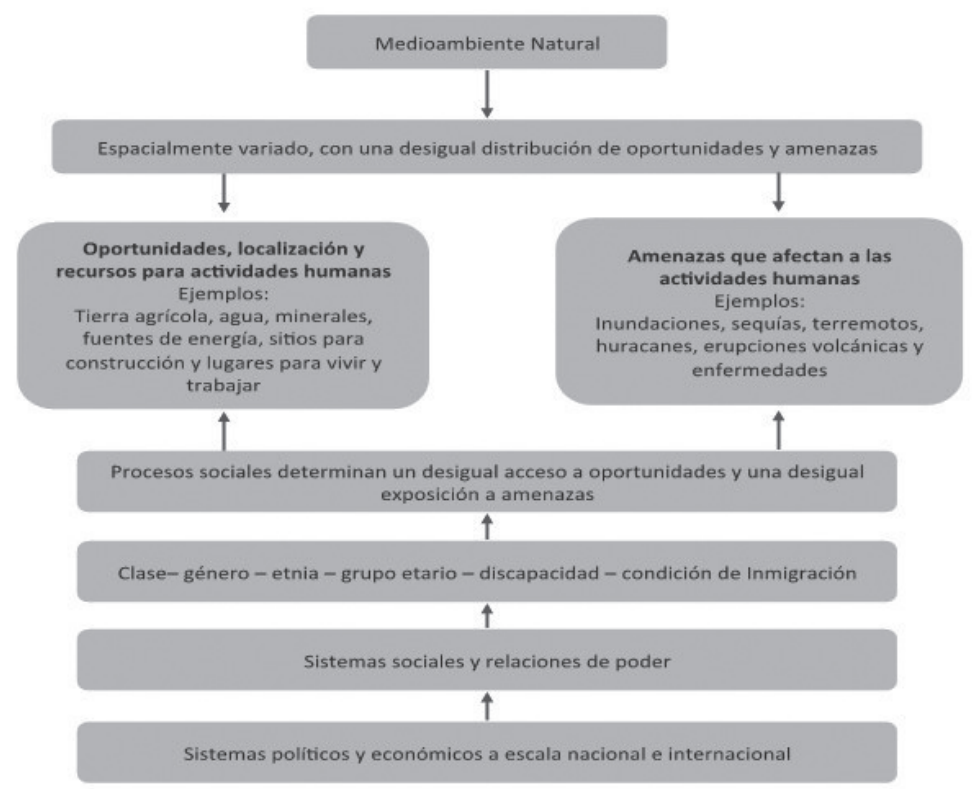

Fuente: Wisner et al., 2003 (traducción de los autores). 
Pese a lo mencionado en materia de planificación urbana y construcción del riesgo, la evolución del pensamiento en materia de planificación no ha reconocido del todo estos aspectos. Mientras que en la historia del urbanismo y del desarrollo urbano, la anticipación y gestión de diversos riesgos urbanos era parte central de la planificación (Mumford, 1968), dando inicio a sistemas de saneamiento, avances en diseño de vivienda y espacio público, gestión de residuos, etc., durante el siglo XX hubo una tendencia muy relevante para enfocarse en aspectos físicos artificiales de los asentamientos, vivienda y vialidad en particular, dejando de lado muchos aspectos ambientales. Efectivamente había una conquista conceptual de la naturaleza por lo artificial, evidencia de la capacidad innovadora de los seres humanos y dejando lo "natural" en segundo plano. Esto sucedió a pesar de los esfuerzos de Federick Olmsted y Patrick Geddes en enfatizar la importancia de los espacios públicos verdes a fines del siglo XIX y principio del siglo XX.

Esto da cuente de que hay diversas formas de entender el concepto de planificación. En el ámbito de la planificación urbana, se entiende la evolución de la disciplina durante el siglo XX principalmente a través de la planificación estratégica, la zonificación (planes maestros) y el diseño urbano (Allmendinger, 2009). No obstante, hay diversos enfoques que han surgido para desafiar esta perspectiva dominante, incluyendo el enfoque comunicacional (Healey, 2005), desde la participación de la comunidad (Jacobs, 1993; Martínez Alier, 2005), o a través del mercado: la acción privada, "el proyecto" y el "New Public Management" (Hood, 2000). Se puede argumentar que todos apuntan al mejoramiento de calidad de vida basado en un fuerte énfasis en la reducción de riesgos, tanto naturales como manufacturados, y que la historia de los asentamientos humanos mantiene esa lógica (Mumford, 1968; Beck, 1992); en la terminología contemporánea, el desarrollo urbano es un proceso de construcción de capacidades adaptivas en los tejidos físicos y socioculturales de los centros urbanos. Sin embargo, durante el siglo XX hubo un proceso de separación de elementos debido a la construcción de comunidades epistémicas modernas y especializadas, enraizadas en diferentes enfoques disciplinares: cambio climático desde la meteorología y ciencias atmosféricas; riesgos desde la ingeniería y las ciencias de la tierra; y planificación del desarrollo urbano desde las ciencias sociales, las artes y la administración (ej. arquitectura y urbanismo). Es evidente que hay más traslapes desde el cambio de siglo, bajo lógicas de interdisciplina y transdisciplina (Max Neef, 2005; Youngblood, 2007; Pohl, 2011), pero la creación de cada comunidad se hizo a espalda de las otras, buscando claridad a través de metodologías disciplinares (ciencia normal), en vez de la interdisciplina y un énfasis en complejidad (ciencia posnormal).

La discusión en el informe SREX (IPCC, 2012) demuestra un esfuerzo importante para volver a vincular estas comunidades y sus genealogías. Ese informe se refiere a la integración de tres grupos de científicos: prevención y gestión de desastres; ciencias básicas del cambio climático; e impactos, adaptación y vulnerabilidad frente al cambio climático (ver Figura $\mathrm{N}^{\circ} 2$ ). Si la localización de los impactos es en las ciudades y sus hinterlands, el tercer grupo tiene un fuerte traslape con la planificación del desarrollo urbano. El documento resume el enfoque de la siguiente manera:

"La evaluación se refiere a la interacción de factores climáticos, medioambientales y humanos que pueden traducirse en impactos y desastres, opciones para la gestión de los riesgos planteados por los impactos y desastres, y el importante papel que desempeñan los factores no climáticos en la determinación de los impactos" (IPCC 2012: 2). 
Figura $\mathrm{N}^{\circ} 2$

Los vínculos entre cambio climático, riesgo y desarrollo

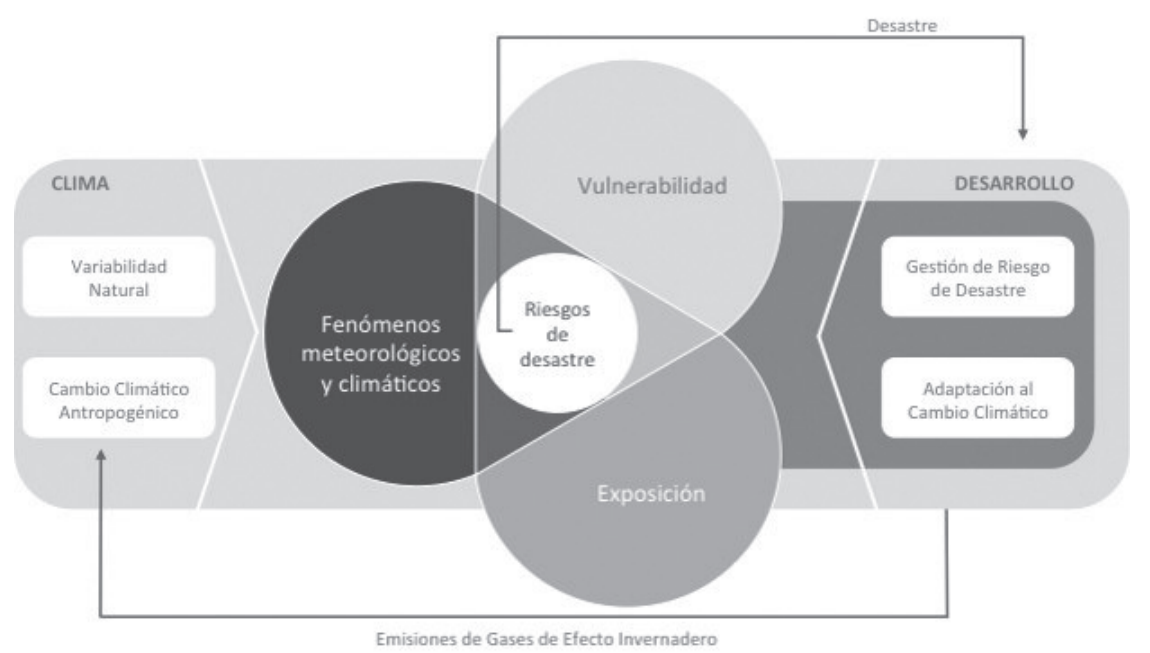

Fuente: IPCC (2012).

Es en esta relación entre factores de riesgos, factores climáticos y factores no climáticos en el contexto urbano que se construye la planificación del desarrollo y lo que se denomina acá: riesgos urbanos. Retomando el IPCC y sus definiciones, estos riesgos urbanos caben en una interpretación amplia de cambio climático, la que no solamente enfatiza los cambios esperados, basado en modelaciones, sino también la actual variabilidad del clima por factores naturales. En este sentido, hay una diferencia con el Artículo 1 de la Convención Marco sobre Cambio Climático de 1994, la cual separa cambio climático y variabilidad climática. El Glosario del IPCC lo define así, incluyendo ambos cambios climáticos abruptos (eventos extremos) y asegurados (cambios en tendencias en temperatura y precipitación):

"Variación del estado del clima identificable (por ejemplo, mediante pruebas estadísticas) en las variaciones del valor medio y/o en la variabilidad de sus propiedades, que persiste durante largos períodos de tiempo, generalmente decenios o períodos más largos. El cambio climático puede deberse a procesos internos naturales o a forzamientos externos tales como modulaciones de los ciclos solares, erupciones volcánicas o cambios antropógenos persistentes de la composición de la atmósfera o del uso del suelo" (IPCC, 2013. Subrayado de los autores).

Para ciudades en particular, el Informe de Síntesis de la Quinta Evaluación indica lo siguiente (IPCC 2014: 16):

"En las zonas urbanas, las proyecciones indican que el cambio climático hará que aumenten los riesgos para las personas, los recursos, las economías y los ecosistemas, incluidos los riesgos derivados del estrés térmico, las tormentas y precipitaciones extremas, las inundaciones continentales y costeras, los deslizamientos de tierra, la contaminación del aire, las sequías, la escasez de agua, la elevación del nivel del mar y las mareas meteorológicas (nivel de confianza muy alto). Los riesgos se agravan para las personas que carecen de infraestructuras $y$ servicios esenciales o viven en zonas expuestas".

Otra aspecto enfatizado en los últimos dos Informes de Evaluación del IPCC (2007, 2014), en particular es el elemento de incertidumbre asociado con la complejidad de las interrelaciones entre factores, por ejemplo niveles de confianza en bandas amplias en lugar de números precisos. Es precisamente por esta razón que es importante entender los fenómenos como interdependientes y multiescalares (panárquicos). Estas construc- 
ciones marcan un contraste importante con las genealogías del siglo XX. A continuación se discute la evolución de ellas, previa a su reintegración en los años recientes.

\section{Agendas internacionales de cambio} climático, planificación urbana y riesgos: carriles diferentes para mismos destinos

En la Figura $N^{0} 3$, se puede ver la evolución de las tres comunidades a través de hitos rele- vantes durante el periodo 1970 hasta la fecha. Fue durante este período que hubo más desarrollo en las comunidades y la generación de una genealogía propia por cada una, a pesar de las evidentes traslapes en términos de las experiencias mismas. A la vez, cada comunidad fue capaz de generar su propia serie de cumbres para compartir el estado del arte y desdibujar los lineamientos de política pública internacional, haciendo de ese modo más complejo el proceso de intervenir en las políticas públicas.

Figura $\mathrm{N}^{\circ} 3$

Línea de tiempo de los hitos principales en torno de cambio climatico, riesgo y desarrollo, 1970-

2014

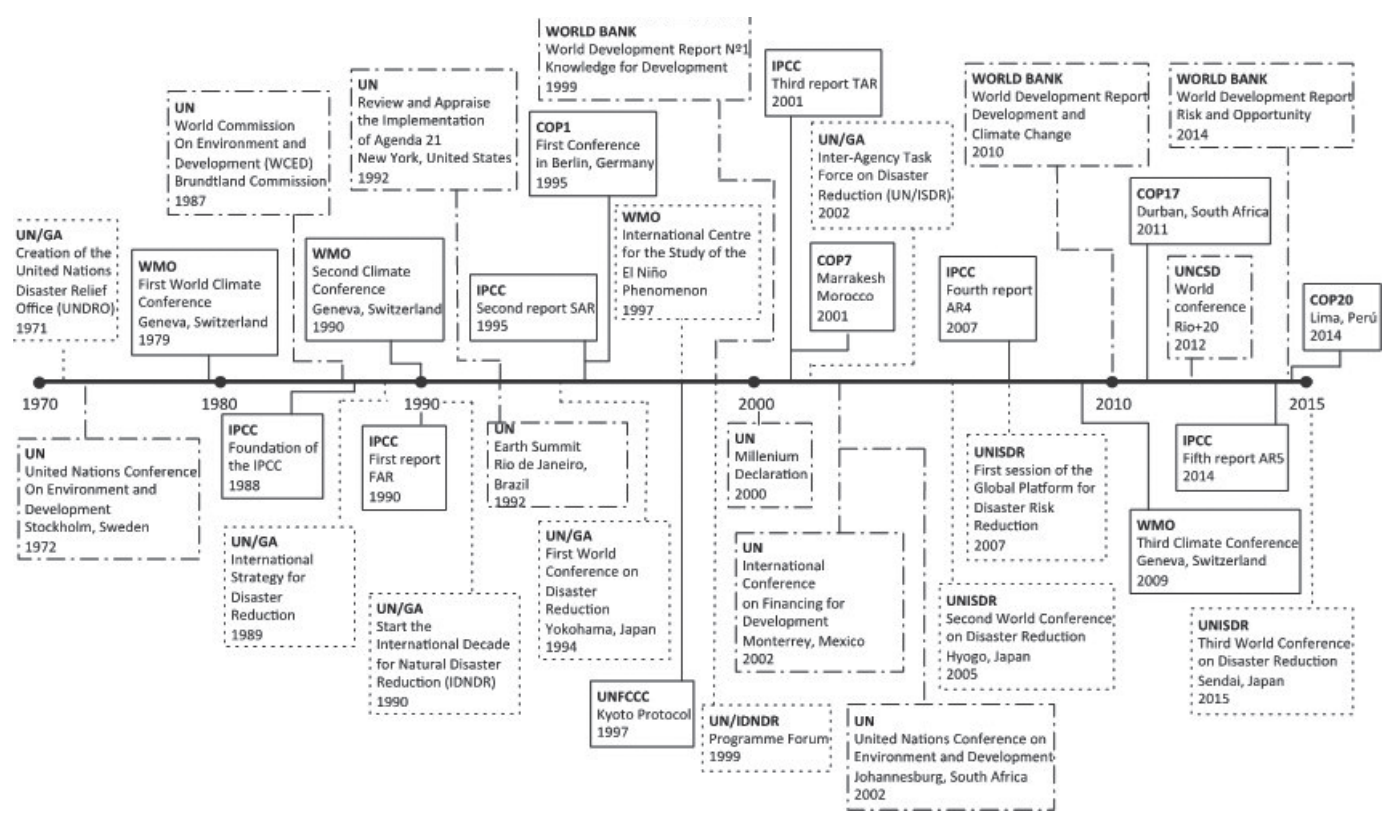

Fuente: Elaboración propia.

Un breve análisis de los contenidos de estas cumbres indican la proximidad en las materias, en particular con referencia a centros urbanos: la anticipación y prevención de riesgos, entendidos como socioecológicos en origen. El siguiente cuadro demuestra esa proximidad (Cuadro $\mathrm{N}^{\circ} 1$ ): 
Cuadro $\mathrm{N}^{\circ} 1$

Traslapes en agendas internacionales

\begin{tabular}{|c|c|c|c|}
\hline Fecha & Reunión & Documento & Cita \\
\hline 1972 & $\begin{array}{l}\text { Estocolmo: Asenta- } \\
\text { mientos Humanos } \\
\text { y Medio Ambiente }\end{array}$ & $\begin{array}{l}\text { Declaración } \\
\text { de Estocolmo. } \\
\text { Principios } 14 \\
\text { y } 15 .\end{array}$ & $\begin{array}{l}\text { "Principio 14.- La planificación racional consti- } \\
\text { tuye un instrumento indispensable para conciliar } \\
\text { las diferencias que puedan surgir entre las exi- } \\
\text { gencias del desarrollo y la necesidad de proteger } \\
\text { y mejorar el medio. Principio 15.- Debe aplicar- } \\
\text { se la planificación a los asentamientos humanos } \\
\text { y a la urbanización con miras a evitar repercu- } \\
\text { siones perjudiciales sobre el medio y obtener } \\
\text { los máximos beneficios sociales, económicos y } \\
\text { ambientales para todos" }\end{array}$ \\
\hline 1976 & $\begin{array}{l}\text { Vancouver: Habi- } \\
\text { tat I }\end{array}$ & $\begin{array}{l}\text { Declaración } \\
\text { de Vancouver. } \\
\text { Recomenda- } \\
\text { ción B.14.b }\end{array}$ & $\begin{array}{l}\text { "La planificación de asentamientos humanos } \\
\text { debe evitar amenazas que pueden conducir a } \\
\text { desastres naturales. La planificación de la re- } \\
\text { construcción después de desastres naturales } \\
\text { o generados por humanos deben ser utilizada } \\
\text { como una oportunidad para mejorar la calidad } \\
\text { del asentamiento entero, su organización funcio- } \\
\text { nal y especial, y el medio ambiente" }\end{array}$ \\
\hline 1992 & $\begin{array}{l}\text { Río de Janeiro: } \\
\text { Medio Ambiente y } \\
\text { Desarrollo }\end{array}$ & $\begin{array}{l}\text { Programa } 21 . \\
\text { Art. } 7.58\end{array}$ & $\begin{array}{l}\text { "El objetivo es poner a todos los países, en par- } \\
\text { ticular los propensos a los desastres, en condi- } \\
\text { ciones de mitigar las consecuencias negativas } \\
\text { para los asentamientos humanos, las economías } \\
\text { nacionales y el medio ambiente de los desastres } \\
\text { naturales o provocados por el hombre" }\end{array}$ \\
\hline 1994 & $\begin{array}{l}\text { Yokohama: Estrate- } \\
\text { gia para un Mundo } \\
\text { más Seguro }\end{array}$ & $\begin{array}{l}\text { Estrategia y } \\
\text { Plan de Ac- } \\
\text { ción. Art. A.3. }\end{array}$ & $\begin{array}{l}\text { "En todos los países, los grupos pobres y en } \\
\text { situación social desventajosa son los que más } \\
\text { sufren a causa de los desastres naturales y son } \\
\text { los que cuentan con menos medios para hacerles } \\
\text { frente. De hecho, los desastres contribuyen a las } \\
\text { perturbaciones sociales, económicas, culturales y } \\
\text { políticas en las zonas urbanas y rurales, en cada } \\
\text { caso de su propia manera. Las concentraciones } \\
\text { urbanas en gran escala son particularmente frági- } \\
\text { les debido a su complejidad y a la acumulación } \\
\text { de población e infraestructura en zonas reduci- } \\
\text { das" }\end{array}$ \\
\hline 1996 & Istanbúl: Habitat II & $\begin{array}{l}\text { Declaración } \\
\text { de Istanbúl } \\
\text { sobre Asenta- } \\
\text { mientos Hu- } \\
\text { manos. Art. } \\
43 .\end{array}$ & $\begin{array}{l}\text { "Nos comprometemos a mejorar la capacidad } \\
\text { de prevención, preparación, mitigación y res- } \\
\text { puesta, con la contribución de redes de coordi- } \\
\text { nación nacionales e internacionales, con el fin } \\
\text { de reducir la vulnerabilidad de los asentamien- } \\
\text { tos humanos a los desastres naturales y los cau- } \\
\text { sados por el ser humano y a ejecutar programas } \\
\text { eficaces después de los desastres en los asen- } \\
\text { tamientos humanos afectados para, entre otras } \\
\text { cosas, satisfacer las necesidades inmediatas, re- } \\
\text { ducir los riegos de futuros desastres y hacer que } \\
\text { los asentamientos humanos reconstruidos sean } \\
\text { accesibles para todos" }\end{array}$ \\
\hline
\end{tabular}


Continuación Cuadro $\mathrm{N}^{0} 1$

\begin{tabular}{|c|c|c|c|}
\hline 2002 & $\begin{array}{l}\text { Johannesburgo: } \\
\text { Desarrollo Susten- } \\
\text { table }\end{array}$ & $\begin{array}{l}\text { Declaración } \\
\text { de Johannes- } \\
\text { burgo. Art. } \\
13 .\end{array}$ & $\begin{array}{l}\text { "El medio ambiente mundial sigue deteriorán- } \\
\text { dose. Continúa la pérdida de biodiversidad; } \\
\text { siguen agotándose las poblaciones de peces; la } \\
\text { desertificación avanza cobrándose cada vez más } \\
\text { tierras fé hacen evidentes los efectos adversos } \\
\text { del cambio del clima; los desastres naturales son } \\
\text { más frecuentes y más devastadores, y los países } \\
\text { en desarrollo se han vuelto más vulnerables, en } \\
\text { tanto que la contaminación del aire, el agua y } \\
\text { los mares sigue privando a millones de seres hu- } \\
\text { manos de una vida digna" }\end{array}$ \\
\hline 2005 & $\begin{array}{l}\text { Hyogo: Reducción } \\
\text { de desastres }\end{array}$ & $\begin{array}{l}\text { Marco Hyogo } \\
\text { de Acción, } \\
2005-2015 . \\
\text { Art. 3.iii.n }\end{array}$ & $\begin{array}{l}\text { "Incorporar la evaluación de riesgo de desastres } \\
\text { en la planificación y gestión urbana en asenta- } \\
\text { mientos humanos sujetos a desastres, en particu- } \\
\text { lar los áreas altamente poblados y de urbaniza- } \\
\text { ción rápida" }\end{array}$ \\
\hline 2012 & $\begin{array}{l}\text { Río +20: Desarro- } \\
\text { Ilo Sustentable }\end{array}$ & $\begin{array}{l}\text { El futuro que } \\
\text { querem os. } \\
\text { Art. } 135\end{array}$ & $\begin{array}{l}\text { "Subrayamos que es importante que en la pla- } \\
\text { nificación urbana se tengan en cuenta la reduc- } \\
\text { ción del riesgo de desastres, la resiliencia y los } \\
\text { riesgos climáticos" }\end{array}$ \\
\hline 2015 & $\begin{array}{l}\text { Sendai: Reducción } \\
\text { de Riesgo de De- } \\
\text { sastres }\end{array}$ & $\begin{array}{l}\text { Marco Sen- } \\
\text { dai, } 2015- \\
\text { 2030. Pream- } \\
\text { ble } 6 .\end{array}$ & $\begin{array}{l}\text { "Enfatizar el trabajo para reducir la exposición y } \\
\text { la vulnerabilidad, para prevenir la generación de } \\
\text { nuevos riesgos de desastre, también se requiere } \\
\text { accountability en la creación de riesgos de de- } \\
\text { sastres a todos niveles." }\end{array}$ \\
\hline
\end{tabular}

Fuente: Elaboración propia.

Si bien se plantean como temas diferentes, con comunidades epistémicas separadas y con agendas políticas paralelas, los objetivos tienden a ser similares. Los traslapes conceptuales y operativos de las tres comunidades epistémicas invitan a cuestionarse la utilidad de emplear conceptos nuevos sin revisar críticamente el desarrollo anterior de otros. A continuación se desarrolla cómo se constituye como meta narrativa el cambio climático, y cómo en ese proceso se desarroIlaron múltiples conceptos que antecedían al cambio climático como tal. En ese ejercicio, la criticidad frente a la utilidad de los conceptos no fue necesariamente la tónica.

\section{Cambio climático y adaptación: meta narrativa contemporánea construida sobre traslapes epistémicos}

Se puede decir que el cambio climático se ha convertido en una meta-narrativa de nuestros tiempos desde su auge en el inicio de los noventa debido a la firma del Marco
Convenio en 1994. Su posición como tema en las instituciones multilaterales, la importancia del IPCC y sus informes en políticas e inversiones, las acciones nacionales y subnacionales (diagnósticos, comunicaciones y políticas), hasta la creación de "mercados de carbono" para buscar una salida transable al problema, indican la preponderancia del concepto. Sin embargo, lo más notable de todo es que este concepto no fue conocido ampliamente hasta los años noventa, y solamente entre meteorólogos y otros especialistas desde los años setenta. Además, pocas conexiones fueron realizadas con otras agendas existentes al mismo tiempo, en particular con la agenda de planificación del desarrollo -lo urbano en particular- y la prevención y gestión de riesgos. Aunque había cierto reconocimiento de los traslapes (ver Cuadro $N^{\circ} 1$ ) entre el Marco Convenio de 1994, la Estrategia de Yokohama (1994) y Habitat II en Istanbúl (1996), no había un proceso sistemático para asegurar un dialogo entre ellos y para maximizar potenciales beneficios mutuos. 
Lo importante que hay que destacar es que el surgimiento del concepto no está relacionado con la experiencia misma del cambio climático, que se evidencia desde el siglo XVIII. 'Cambio climático' como concepto fue una construcción social para captar una serie de elementos: ciencia básica, impactos diversos episódicos y graduales, y un posicionamiento sociopolítico a distintas escalas frente a estas experiencias. La curva 'hockey stick' identificando la velocidad en el aumento de temperatura asociado con los gases de efectos invernadero fue emblemática en este proceso, y por esta misma razón ha sido un blanco para los 'climate deniers' en años posteriores (Edwards, 2009). Como consecuencia, el 'cambio climático' se transformó en el principal acuerdo de la Cumbre de Medio Ambiente y Desarrollo en Río de Janeiro en 1992. Desde esta fecha, su protagonismo como meta-narrativa del desarrollo contemporáneo fue consolidado, por ejemplo en el premio Nobel para el IPCC y los científicos participantes en 2007 (también para Al Gore y su documental La Verdad Incómoda).

Cuando los conceptos gozan de gran popularidad se tienden a desligar de su significado original, o bien se hace referencia a ellos sin necesariamente tener un conocimiento preciso sobre su definición. La adaptación puede ser contextualizada en ese marco, pues antes de 1992 no era utilizada en función del cambio climático, situación que comenzó a cambiar tras la publicación de la Convención Marco sobre Cambio Climático de las Naciones Unidas (UNFCCC) (Schipper \& Burton, 2009). En términos prácticos la adaptación siempre ha estado presente en los ecosistemas y en las sociedades, no obstante solo hace dos décadas la comunidad científica y los tomadores de decisiones comenzaron a darle importancia a la búsqueda de estrategias y planes orientados a que la humanidad se logre adaptar al cambio climático (Schipper \& Burton, 2009).

Smithers \& Smit (2009) señalan que la adaptación no tiene su significado necesariamente en el cambio climático. El origen del concepto, según ellos, se encuentra en las ciencias naturales, más específicamente en la biología de la población y en la ecología evolutiva. En ese contexto la adaptación representa a las características que permita a un organismo determinado vivir y reproducirse en el ambiente que habita, por lo que una buena adaptación implica la sobrevivencia de una especie o un ecosistema. De mismo modo señalan que el término ha sido adoptado por diversos campos de las ciencias sociales, y en esos casos su carga conceptual se traduce en cómo los sistemas económicos y sociales, así como sus individuos pueden persistir ante transformaciones ambientales. El aporte en el área recae en que los seres humanos pueden manejar y planificar su adaptación, por lo cual en ellos posee una dimensión reactiva y proactiva, a diferencia de otros seres vivos que poseen una adaptación plenamente reactiva.

Pelling (2011) señala que el concepto de adaptación es precedido por coping en al menos treinta años en materia de respuestas humanas ante cambios ambientales, y los diferentes términos posteriores asociados a la temática podrían ser categorizados como una "re-invención de la rueda" (Schipper \& Pelling, 2006). Si bien, coping representa procesos reversibles y la adaptación procesos irreversibles, en la práctica son conceptos paralelos que sirven a similares intereses teóricos pero de diferente origen (Pelling, 2011). De todos modos, la sutil distinción entre coping y adaptación radica en que lo primero alude a la capacidad de hacer frente a los impactos del cambio climático en base a las prácticas e instituciones establecidas, a diferencias de la adaptación que representa al proceso en el cual se pueden generar cambios en las prácticas e instituciones que se relacionan con las causas y efectos del cambio climático (Pelling, 2011). Esta discusión de los mecanismos para enfrentar procesos de adaptación también tiene sus raíces en la discusión de riesgo frente a los desastres, y su base social, incluyendo la construcción social de los desastres como fenómeno (ver Wisner et al., 2003).

Retomando a Schipper \& Burton (2009), ellos se suman a la discusión respecto a las diferentes nociones de adaptación, no obstante señalan otra línea que será fundamental para encauzar en dirección al cambio climático. Esta viene del trabajo realizado por Gilbert White en su obra Human Adjustment to Floods (1945 en Schipper \& Burton, 2009), el cual opta por utilizar el término human ad- 
justment antes que adaptación, para explicar que la problemática de las inundaciones no pasa por obras ingenieriles sobre control de flujos, sino por acciones más amplias como la planificación de usos de suelo, alertas preventivas o planes de evacuación. Si bien el término adaptación fue utilizado en diversas áreas, como se señaló anteriormente, fue la Convención Marco sobre Cambio Climático de 1992 la que lo insertó en la temática de cambio climático. Si bien este documento no definió adaptación literalmente, abrió la senda para que el concepto fuese utilizado en la materia, y para que a su vez sea distinguido de mitigación (Schipper \& Burton, 2009).

Füssel (2007) señala que en realidad la adaptación es un conjunto de actividades humanas que no se encuentra bien definido. En efecto, dicha indefinición deviene de la existencia de una gran cantidad de enfoques para analizarla. Del mismo modo, y llevando la adaptación al plano del cambio climático, Füssel (2007: 268) señala que esta vinculación tiene tanto elementos nuevos como elementos previos. En efecto, afirma que hay tres aspectos de la adaptación que son previos al cambio climático. Primero, las sociedades históricamente han tratado de hacer el mejor uso posible de sus condiciones climáticas, independiente de los resultados respectivos. Segundo, varias actividades vinculadas a la adaptación al cambio climático no deben su origen a este proceso (gestión de riesgo de desastre, gestión costera, gestión de recursos, planificación urbana y regional, salud pública, y extensión agrícola). Y tercero, en repetidos casos los métodos y herramientas empleados en la adaptación al cambio climático vienen de la gestión de riesgos naturales (Willows \& Connell, 2003). De todos modos, el autor también agrega una serie de características sin precedentes que hacen novedosa la adaptación al cambio climático, como por ejemplo las condiciones climáticas y la magnitud de los cambios asociados, así como los avances científicos y metodológicos en materia de monitoreo, entre otros factores.

Como bien señala Füssel (2007), la adaptación al cambio climático comparte varios elementos con la gestión del riesgo, no obstante implica una serie de desafíos asociados a las incertidumbres que implica el cambio climático. Esta relación es clave para el presente trabajo, pues opera como la piedra angular del argumento. En efecto, es en ese traslape entre el manejo de los riesgos naturales y la adaptación al cambio climático en donde se deben encontrar sinergias para producir los cambios necesarios, más que operar como dos fuerzas paralelas.

Wilson (2007) expone un interesante trabajo que no conceptualiza los impactos del cambio climático en las personas como tal, sino se enfoca en los impactos potenciales sobre las políticas de planificación local en el Reino Unido, así como en su potencialidad para ser un aporte en el proceso de adaptación. Cabe destacar sus resultados respecto a las inundaciones donde señala que:

"La política nacional de adaptación y los lineamientos de riesgo de inundaciones tienen una larga tradición en el Reino Unido: planes de uso de suelos requieren la consideración de la zona de inundación desde 1947" (p. 616)

Wilson (2007) señala que si bien entre el 2000 y 2005 (periodo en que realizó su estudio) aumentaron crecientemente las inundaciones en las localidades analizadas, la minoría de ellas vinculaban el cambio climático a las inundaciones. En esto se debe considerar que la mitad de los casos estudiados hacía alusión al cambio climático, lo que no significó una relación de este con los riesgos asociados a inundación. La misma inferencia construye Michael Hebbert (2014) en su análisis de la climatología urbana y sus orígenes, argumentando que tiene una historia larga en la planificación urbana -en el trabajo de Stadtklima (1937) de Albert Kratzer por ejemplo- que no ha sido reconocido en forma adecuada por la comunidad de cambio climático.

En esta línea también puede ser considerado el trabajo realizado por Sofie Storbjörk (2007), el cual muestra los desafíos de la adaptación al cambio climático en dos ciudades de Suecia, tomando como elementos centrales su vinculación a los instrumentos de planificación y a la gestión de riesgos naturales. Lo valioso del enfoque empleado

\footnotetext{
5 Traducción de los autores.
} 
por la autora es que analiza críticamente los avances en materia de planificación urbana y riesgos naturales como planos elementales para el proceso de adaptación al cambio climático, más que buscar implementar políticas o planes de forma paralela. Independiente de que Storjbjök (2007) encuentre una gran cantidad de dificultades políticas para los progresos de los dos ejes, plantear la discusión desde las condiciones existentes es una potencialidad.

Si bien vincular la adaptación al cambio climático fue un hecho inflexivo por parte de la UNFCC, y que sin duda es relevante en el contexto de cambio global que vivimos, la discusión conceptual da cuenta de que no es algo nuevo en su totalidad. Gilbert White (1945) invita a pensar de qué modo eran conceptualizadas problemáticas similares antes de que el tema fuese tratado como cambio climático. Si bien el cambio climático es relativamente reciente, su forma operativa (adaptación al cambio climático) posee raíces en iniciativas que ya se encuentran operando. No obstante lo anterior, esto no quiere decir que estas iniciativas sean las idóneas ni que no deban ser evaluadas y criticadas.

La falta de trabajo para unir las agendas de planificación del desarrollo urbano, riesgos y desastres, y cambio climático, ha generado diversos problemas a nivel nacional y subnacional en términos de organización institucional, competencias y financiamiento. A través del caso chileno -con fenómenos hidrometeorológicos en particular- se puede ver los evidentes traslapes y la necesidad de seguir los lineamientos del informe SREX del IPCC (2012) y aterrizar los desafíos de cambio climático y riesgos de desastre dentro de un marco más amplio de 'riesgos urbanos' de índole natural y sociocultural, con un reconocimiento pleno de la complejidad de las interrelaciones involucradas.

\section{Cambio climático y riesgos naturales en la planificación urbana chilena}

Si bien las causas del cambio climático se encuentran en discusión, sus efectos son perceptibles en diferentes partes del mundo. En el caso chileno, pese a que las tendencias se basan en la disminución de las precipitaciones (acumulada anual) para gran parte del país, especialmente en la zona centro sur (Garreud, 2011), se espera un aumento en la intensidad de precipitación (pp/24hrs). Además, se debe agregar que se elevará la isoterma $0^{\circ} \mathrm{C}$ entre 300 y $500 \mathrm{~m}$, lo que se traducirá en un aumento de la superficie de captación de precipitaciones líquidas (DGF, 2006). Adicionalmente la sucesión del "El niño oscilación sur" (ENOS) es cada vez más irregular, lo que alterara considerablemente el régimen de precipitación (IPCC, 2002). Estas tres afirmaciones instan a poner particular atención a los riesgos hidrometeorológicos, dado que probablemente la frecuencia e intensidad de estas amenazas aumentará. Estas condiciones generan un nuevo escenario en materia de riesgos climáticos, el cual sin duda requiere de mayores compromisos y acciones concretas para disminuir los niveles de vulnerabilidad de la población. Como consecuencia, hay conexiones directas con la planificación de usos de suelo y la zonificación de centros urbanos y sus periferias.

Pese a lo anterior, si bien el cambio climático marca un nuevo contexto en materia de riesgos hidrometeorológicos, no es del todo novedoso. Históricamente las ciudades chilenas han sido afectadas por eventos de esta naturaleza, y efectivamente han causado fuertes estragos sobre la población. Si bien el cambio climático ha influido e influye en la periodicidad y magnitud de esos eventos, los asentamientos urbanos en Chile poseen una importante experiencia en materia de 
desastres naturales. Esto genera un escenario de gran complejidad, dado que el $90,2 \%$ de su población habita en espacios urbanos, y ya sea por el escaso planeamiento territorial, o por las excesivas presiones del mercado inmobiliario, parte importante del área de las ciudades se superpone con áreas de riesgo natural (Arenas et al. 2010). Los eventos más frecuentes tienden a ser las inundaciones, especialmente en Santiago (Ebert et al. 2010) donde la expansión urbana ha presentado una fuerte tendencia hacia sectores de mayor pendiente en los pies de monte (Muller et al., 2011). Complementario a esto ocurren deslizamientos de materiales sólidos, las cuales son gatillados por intensos eventos de precipitación conjugados con las características geográficas y geológicas de Chile (Sepúlveda et al., 2006).

La confluencia entre el escenario del cambio climático y la experiencia de las ciudades chilenas en materia de riesgos hidrometeorológicos implica significativos desafíos en materia de gestión urbana. No obstante, es fundamental analizar la forma en que han sucedido los eventos en el pasado, sus alcances, y sobre todo los umbrales que definirán las futuras ocurrencias de desastres naturales. Sin ese ejercicio se corre el riesgo de aceptar el escenario del cambio climático como algo totalmente nuevo, y de olvidar la experiencia que tienen las ciudades chilenas en la materia, pese a que sea dolorosa de recordar. El Cuadro $N^{\circ} 2$ expone los principales eventos de carácter hidrometeorológico que han afectado a las ciudades más pobladas del país entre 1987 y 2011. El común denominador de estos eventos es que todos presentaron una considerable cantidad de personas afectadas, o bien de viviendas dañadas, y siempre han tenido fuerte presencia en las zonas urbanas. Si bien ciertos eventos (Antofagasta, 1991 y Santiago, 1993) son representados principalmente por deslizamiento de materiales sólidos, estos son detonados por fuertes eventos de precipitaciones concentradas en días seguidos, o bien en un día.

Cuadro $\mathrm{N}^{\circ} 2$

Principales eventos hidrometeorológicos en las cinco ciudades más pobladas hasta el 2011

\begin{tabular}{|c|c|c|c|}
\hline Fecha & $\begin{array}{c}\text { Principal foco } \\
\text { urbano }\end{array}$ & Evento & Impactos* \\
\hline 28-7-1987 & Antofagasta & $\begin{array}{l}22,8 \text { mm de precipitación acumu- } \\
\text { lada en } 24 \text { horas. Se produjeron } \\
\text { varios deslizamientos en la ciudad. }\end{array}$ & $\begin{array}{l}-2.000 \text { damnificados } \\
\text { (Arcadis GEOTECNIA, } \\
2008 \text { ) }\end{array}$ \\
\hline 18-6-1991 & Antofagasta & $\begin{array}{l}42 \mathrm{~mm} \text { de precipitación acumulada } \\
\text { en } 24 \text { horas. Se produjeron varios } \\
\text { deslizamientos en la ciudad, siendo } \\
\text { Villa el Salto el lugar más afectado. }\end{array}$ & $\begin{array}{l}\text { - } 2.464 \text { viviendas daña- } \\
\text { das } \\
\text { - } 493 \text { viviendas destrui- } \\
\text { das } \\
\text { - } 92 \text { muertos } \\
\text { - } 16 \text { desaparecidos } \\
\text { ("El Mercurio de An- } \\
\text { tofagasta", S/F, Junio, } \\
\text { 2002: "Las heridas del } \\
\text { aluvión") }\end{array}$ \\
\hline 03-5-1993 & Santiago & $\begin{array}{l}\text { Fuerte intensidad de precipitaciones } \\
\text { provocó un aluvión encauzado en } \\
\text { la quebrada de Macul, y consi- } \\
\text { guientemente desbordó el canal Las } \\
\text { Perdices y San Carlos. }\end{array}$ & $\begin{array}{l}\text { - } 200 \text { viviendas destrui- } \\
\text { das } \\
\text { - } 950 \text { damnificados } \\
\text { - } 16 \text { muertos } \\
\text { (Naranjo y Varela, 1996) }\end{array}$ \\
\hline
\end{tabular}


Continuación Cuadro № 2

\begin{tabular}{|c|c|c|c|}
\hline Fecha & $\begin{array}{c}\text { Principal foco } \\
\text { urbano }\end{array}$ & Evento & Impactos* \\
\hline 6-1997 & $\begin{array}{l}\text { - Coquimbo/La } \\
\text { Serena } \\
\text { - Santiago } \\
\text { - Valparaíso } \\
\text { - Concepción }\end{array}$ & $\begin{array}{l}\text { Dos temporales consecutivos pre- } \\
\text { cedidos por cuatro años de sequía, } \\
\text { los cuales fueron particularmente } \\
\text { graves al norte de Santiago, lo que } \\
\text { se debe al fenómeno ENOS**. En } \\
\text { Santiago, el año } 1997 \text { tuvo un supe- } \\
\text { rávit de } 127 \% \text { de precipitaciones, } \\
\text { altamente ligado a estos eventos }\end{array}$ & $\begin{array}{l}\text { - } 87.000 \text { damnificados } \\
\text { - } 10.000 \text { albergados } \\
\text { (ONEMI, 1997) }\end{array}$ \\
\hline 6-2002 & $\begin{array}{l}\text {-Valparaíso } \\
\text { - Santiago } \\
\text { - Concepción }\end{array}$ & $\begin{array}{l}\text { Sistemas frontales desarrollados e } \\
\text { intensos generaron fuertes lluvias } \\
\text { durante gran cantidad del mes. Se } \\
\text { registraron } 542 \text { puntos críticos en la } \\
\text { Región Metropolitana, siendo esta y } \\
\text { la de Valparaíso las más afectadas. }\end{array}$ & $\begin{array}{l}\text { - } 70.000 \text { damnificados } \\
\text { - } 5.600 \text { albergados } \\
\text { - } 14 \text { muertos } \\
\text {-8.300 viviendas dañadas } \\
\text { ("BBCmundo.com", } 8 \text { de } \\
\text { Junio 2002: "Chile: } 70 \\
\text { mil damnificados") }\end{array}$ \\
\hline 8-2002 & - Concepción & $\begin{array}{l}\text { Constantes eventos de precipita- } \\
\text { ción produjeron desbordes en los } \\
\text { ríos Biobío y Andalién y del estero } \\
\text { Nonguén. }\end{array}$ & $\begin{array}{l}\text { - } 3.000 \text { damnificados } \\
\text { - } 500 \text { viviendas dañadas } \\
\text { (Sitio web BBC Mun- } \\
\text { do, S/F, Agosto 2002: } \\
\text { "Fuertes inundaciones en } \\
\text { Chile") }\end{array}$ \\
\hline $7-2006$ & $\begin{array}{l}\text { - Coquimbo/La } \\
\text { Serena } \\
\text { - Santiago } \\
\text { - Valparaíso } \\
\text { - Concepción }\end{array}$ & $\begin{array}{l}\text { Una serie de eventos de precipi- } \\
\text { taciones afectaron entre la IV y XI } \\
\text { Región, siendo la Región del Biobío } \\
\text { la más afectada, provocando varias } \\
\text { inundaciones, desbordes de ríos y } \\
\text { anegamientos. }\end{array}$ & $\begin{array}{l}\text { - } 50.000 \text { damnificados } * * * \\
\text { - } 25 \text { muertos } \\
\text { - } 750 \text { viviendas destrui- } \\
\text { das } \\
\text { - } 34 \text { viviendas dañadas } \\
\text { (GORE Biobío, 2007) }\end{array}$ \\
\hline $6-2011$ & $\begin{array}{l}\text { - Coquimbo/La } \\
\text { Serena }\end{array}$ & $\begin{array}{l}\text { Dos periodos de altas precipitacio- } \\
\text { nes con escasa diferencia lograron } \\
\text { un superávit de } 666 \% \text {, a la fecha, } \\
\text { en la Región de Coquimbo, alcan- } \\
\text { zando } 96 \text { mm de precipitación } \\
\text { acumulada en } 24 \text { hrs. }\end{array}$ & $\begin{array}{l}\text { - } 3.257 \text { damnificados } \\
\text { - } 2.742 \text { casa dañadas } \\
\text { ("La Tercera", S/f, Junio } \\
\text { 2011, "Lluvias en la IV } \\
\text { Región registran su- } \\
\text { perávit histórico y cae } \\
\text { nevazón" y "Temporal } \\
\text { deja inundaciones en La } \\
\text { Serena y Coquimbo") }\end{array}$ \\
\hline
\end{tabular}

* La caracterización de la descripción e impactos varía en función de la información disponible en los distintos medios de prensa en los cuales se recopiló la información

${ }^{* *}$ El niño oscilación sur.

${ }^{* * *}$ Los datos son solo para la región del Biobio.

Fuente: Elaboración propia. 
Por ejemplo para el caso de Antofagasta se han desarrollado cinco aluviones entre 1930 y 1991, con diversos grados de impacto. Basta con intensidades de precipitación superiores a $30 \mathrm{~mm} / 24 \mathrm{~h}$ para que se activen flujos aluvionales (Vargas et al., 2000). Por su parte, como se mencionó anteriormente, el caso del Área Metropolitana de Santiago también se encuentra altamente expuesta a deslizamientos asociados a eventos hidrometeorológicos extremos, como por ejemplo el aluvión de la Quebrada de Macul en 1993. Este evento es producto de la combinación entre intensidades de precipitación superiores a $12 \mathrm{~mm} /$ hora y una elevación de la isoterma $0^{\circ} \mathrm{C}$ sobre $4.000 \mathrm{msnm}$, lo que significó un incremento de tres a cuatro veces en el área de recepción pluvial en el pie de monte de Santiago (Garreud y Rutllant, 1996). Ambos eventos marcan tristemente la experiencia chilena $^{6}$ en materia de deslizamientos de materiales sólidos, los cuales fueron gatillados por la superación de umbrales hidrometeorológicos específicos. No olvidar estas experiencias es fundamental para repensar tanto la gestión de riesgos naturales, así como también los desafíos que representa el cambio climático.

Asimismo, eventos de precipitación extrema por sí solos, también han sido suficientes para generar escenarios, inundaciones y anegamientos en las diferentes ciudades chilenas. Para el caso del Área Metropolitana de Valparaíso, entre los años 1980 y 2000 ocurrieron 45 eventos de emergencia asociados a situaciones de precipitación, los cuales en su mayoría sucedieron mientras se desarrollaba el fenómeno ENOS. Del total de emergencias, 25 fueron inundaciones graduales y 20 fueron inundaciones abruptas, de estas últimas algunas superaron incluso los $100 \mathrm{~mm} / 24 \mathrm{hrs}$, y 11 de los eventos abruptos sucedieron en periodos neutrales (no ENOS) (Romero y Mendoça, 2009). Del mismo modo, el Área Metropolitana de Concepción ha tenido una considerable expansión urbana en dirección a las zonas de amenazas naturales. Entre 1960 y 1990, se registraron 132 eventos de anegamiento y 33 inundaciones en la comu-

\footnotetext{
6 A esto se debe agregar el aluvión de la Región de Atacama el año 2015, el cual no fue considerado en el presente trabajo.
}

na de Concepción, mientras que Talcahuano en el mismo periodo sufrió 67 anegamientos y 5 inundaciones (Mardones y Vidal, 2001). También el Área Metropolitana de Santiago ha experimentado los mismos problemas, en tanto la intensidad de precipitaciones promedio es excesivamente sobrepasada cada diez años (Stappung, 1999).

Las ciudades chilenas han tenido eventos de deslizamientos, inundaciones y anegamientos con anterioridad a la discusión de cambio climático. El escenario del cambio climático trae consigo una serie de nuevos desafíos, no obstante parte de las expresiones problemáticas de este escenario no son nuevas para las ciudades chilenas. Pese a que la experiencia en materia de eventos hidrometeorológicos no ha sido positiva, debe ser considerada para tener una reflexión crítica frente al nuevo proceso. En ese sentido, lo determinante se encuentra en analizar cómo estas experiencias han sido integradas en materia de acciones concretas. En el siguiente apartado se aborda este punto en materia de instrumentos legales.

\section{Riesgos en la planificación urbana: lentos avances}

La ingrata experiencia en materia de desastres naturales de las ciudades chilenas ha tenido un lento proceso de asimilación en materia de disposiciones legales, las cuales han tendido a ser reactivas frente a los distintos eventos. Ejemplo de eso es la ley de construcciones asísmicas, la cual fue promulgada tras el terremoto de Talca en 1928, que fue la base de la Ley General de Urbanismo y Construcción de 1935 (Arenas et al. 2010). Estos avances normativos sentaron las bases de lo que serán las disposiciones legales en materia de diseño y construcción, así como también respecto lo que serán los planes reguladores comunales, sobre todo tras los terremotos de Chillán en 1939 y Valdivia en 1960, dado que se hará manifiesta la necesidad de que las normas de riesgos se ajusten a las distintas localidades. Si bien los avances en materia normativa fueron impulsados por riesgos sísmicos, sobre todo por su impacto, es dentro de esa senda donde fueron siendo incorporados los elementos orientados a riesgos hidrometeorológicos. 
Si bien no se definieron riesgos naturales en sus inicios, en 1976 se precisaron las zonas de restricción dentro de la Ley General de Urbanismo y Construcción (LGUC), la cual estipuló que esas zonas no deben ser edificadas por su especial naturaleza y ubicación (Artículo $60^{\circ}$ ). Ese fue la primera ley con la cual los instrumentos de planificación urbana fueron integrados, así como también administrados por el Ministerio de Vivienda y Urbanismo (creado en 1965) y no por el Ministerio de Obras Públicas. Sin embargo, fue solamente en 1992 que los riesgos naturales específicos fueron definidos en la ordenanza de planificación, a pesar de los avances a nivel internacional con lineamientos claros, como por ejemplo la Declaración de Vancouver (1976). En la ordenanza de la
LGUC (OGUC) son separadas las áreas de riesgo en zonas de restricción y en zonas no edificables. Estas corresponden a zonas que, por razones fundadas, se deban limitar el tipo de construcciones o establecer requisitos determinados para que puedan ser utilizadas las zonas en cuestión. Las áreas de riesgo pueden ser modificadas mediante medidas de mitigación, y las tipologías específicas de riesgo reconocen inundaciones, avalanchas, actividad volcánica o de origen antrópico (Artículo $2.1 .17^{\circ}$ ). Estas áreas deben ser definidas en los planes reguladores comunales. La Figura $N^{\circ} 4$ sintetiza la jerarquía legal de los instrumentos asociados a riesgos naturales en la planificación urbana, así como también sus definiciones conceptuales.

Figura $\mathrm{N}^{\circ} 4$

Niveles de acción respecto a riesgos naturales en la planificación urbana en Chile

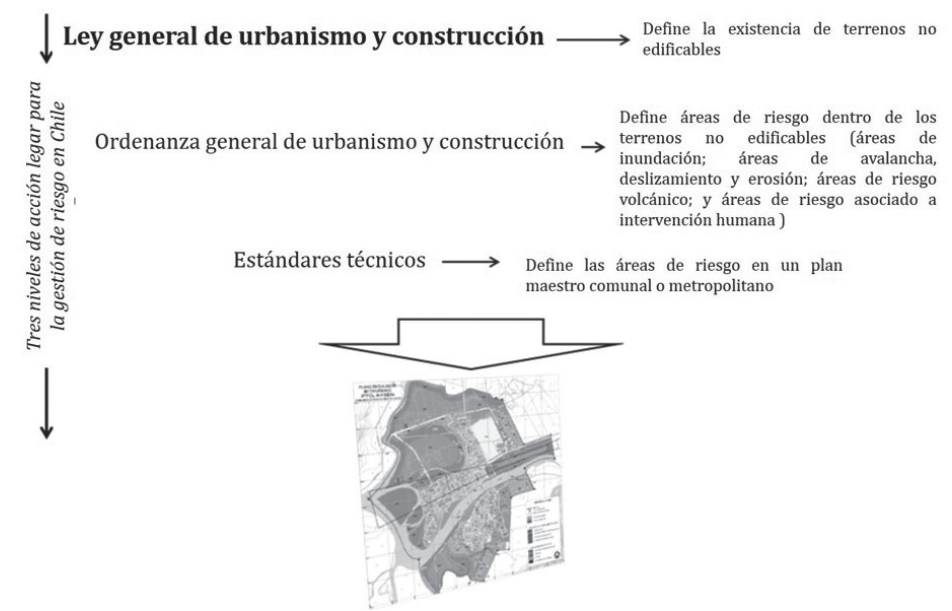

Fuente: Elaboración propia.

Por lo tanto, es a partir de lo afirmado en la LGUC desde donde se desprenden los aspectos que deben considerar los instrumentos de planificación. En ellos los riesgos naturales son categorizados como "zonas no edificables", y no se hace explícita la importancia del manejo y la mitigación de éstos. Si bien se debe reconocer que la existencia de planes de uso de suelo ya es una potencialidad, la escueta conceptualización de los riesgos naturales en los planes permite pensar que los instrumentos de planificación en Chile no están preparados para la adaptación ni para la mitigación ante el cambio climático. Es correcto identificar las áreas propensas a riesgos naturales, y efectivamente es un primer paso. No obstante limitarse a restringir usos en lugar de definir planes de manejo es un error estratégico de cara a enfrentar el cambio climático, por lo cual estos instrumentos deben ser revisados basado en los lineamientos del informe SREX (IPCC, 2012).

Un problema de que la planificación urbana en materias de riesgo se haga efectiva 
en los planes reguladores comunales, es que los tiempos y capacidades de cada comuna son sumamente variados. De las ciudades revisadas en el Cuadro $N^{\circ} 3$, todas cuentan con algún instrumento de planificación vigente, independiente de que no necesariamente todas hayan tenido instrumento vigente al suceder los desastres mencionados en el punto anterior. En la Tabla 2 se expone una síntesis respecto a los planes reguladores para cada una de las zonas urbanas estudiadas. Se considera como ejes fundamentales las unidades administrativas, la existencia de un plan unificado para la totalidad del área urbana, la antigüedad del plan, la forma en que definen los riesgos naturales y las acciones específicas que comprometen frente a estas zonas.

Cuadro $N^{\circ} 3$

Instrumentos de planificación existentes para las ciudades en estudio y su planificación en materia de riesgos naturales

\begin{tabular}{|c|c|c|c|c|c|}
\hline Ciudad & $\begin{array}{l}\mathrm{N}^{\circ} \text { de } \\
\text { unidades } \\
\text { adminis- } \\
\text { trativas }\end{array}$ & $\begin{array}{l}\text { Plan } \\
\text { unifica- } \\
\quad \text { do }\end{array}$ & Año & $\begin{array}{l}\text { Definición de } \\
\text { riesgo }\end{array}$ & Acciones específicas \\
\hline Antofagasta & 1 & ----- & 2002 & $\begin{array}{l}\text { Deslizamientos y } \\
\text { zonas de protec- } \\
\text { ción de tsunamis }\end{array}$ & $\begin{array}{l}\text { - Abrir caminos } \\
\text { y generar vías de } \\
\text { evacuación } \\
\text { - Áreas Verdes } \\
\text { - Sistema urbano } \\
\text { aluvial } \\
\text { - Piscinas de con- } \\
\text { tención aguas arriba }\end{array}$ \\
\hline \multirow{3}{*}{$\begin{array}{l}\text { Coquimbo/ } \\
\text { La Serena }\end{array}$} & \multirow{3}{*}{2} & \multirow{3}{*}{ No } & 1984 & $\begin{array}{l}\text { Áreas de } \\
\text { restricción por } \\
\text { riesgo. } \\
\text { (Pendientes sobre } \\
40 \% \text { ) }\end{array}$ & $\begin{array}{l}\text { - Restricciones de } \\
\text { uso de suelo }\end{array}$ \\
\hline & & & \multirow{2}{*}{2004} & \multirow{2}{*}{$\begin{array}{l}\text { Áreas de } \\
\text { restricción }\end{array}$} & $\begin{array}{l}\text { - Restricciones de } \\
\text { uso de suelo }\end{array}$ \\
\hline & & & & & $\begin{array}{l}\text { - Usos condicio- } \\
\text { nados el bordes } \\
\text { fluviales }\end{array}$ \\
\hline
\end{tabular}


Continuación Cuadro $N^{\circ} 3$

\begin{tabular}{|c|c|c|c|c|c|}
\hline Ciudad & $\begin{array}{l}\mathrm{N}^{\circ} \text { de } \\
\text { unidades } \\
\text { adminis- } \\
\text { trativas }\end{array}$ & $\begin{array}{l}\text { Plan } \\
\text { unifica- } \\
\text { do }\end{array}$ & Año & $\begin{array}{l}\text { Definición de } \\
\text { riesgo }\end{array}$ & Acciones específicas \\
\hline \multirow[b]{2}{*}{ Gran Santiago } & \multirow[b]{2}{*}{37} & \multirow[b]{2}{*}{ Sí } & \multirow[b]{2}{*}{1994} & $\begin{array}{l}\text { - Riesgo de origen } \\
\text { natural }\end{array}$ & $\begin{array}{l}\text { - Restricciones de } \\
\text { uso de suelo }\end{array}$ \\
\hline & & & & $\begin{array}{l}\text { Alto riesgo para } \\
\text { asentamientos } \\
\text { humanos }\end{array}$ & $\begin{array}{l}\text { - Usos condicio- } \\
\text { nados asociados al } \\
\text { tipo de restricción }\end{array}$ \\
\hline \multirow{5}{*}{ Gran Valparaíso } & \multirow[b]{2}{*}{6} & \multirow{5}{*}{ Sí } & & $\begin{array}{l}\text { - Áreas de uso } \\
\text { forestal }\end{array}$ & - Forestación \\
\hline & & & 1965 & $\begin{array}{l}\text { - Restricciones } \\
\text { geotécnicas }\end{array}$ & $\begin{array}{l}\text {-Usos condiciona- } \\
\text { dos asociados al } \\
\text { tipo de restricción }\end{array}$ \\
\hline & \multirow{3}{*}{8} & & 2013 & $\begin{array}{l}\text { - Zonas de protec- } \\
\text { ción }\end{array}$ & $\begin{array}{l}\text { - Restricciones de } \\
\text { uso de suelo }\end{array}$ \\
\hline & & & $\begin{array}{l}\text { (aproba- } \\
\text { ción pen- } \\
\text { diente) }\end{array}$ & $\begin{array}{l}\text { - Áreas de protec- } \\
\text { ción ante riesgo } \\
\text { natural }\end{array}$ & $\begin{array}{l}\text { - Usos condicio- } \\
\text { nados asociados al } \\
\text { tipo de restricción }\end{array}$ \\
\hline & & & & $\begin{array}{l}\text { - Áreas de valor } \\
\text { natural }\end{array}$ & \\
\hline \multirow{2}{*}{$\begin{array}{l}\text { Gran Concep- } \\
\text { ción }\end{array}$} & \multirow[t]{2}{*}{10} & \multirow[t]{2}{*}{ Sí } & \multirow[t]{2}{*}{2003} & $\begin{array}{l}\text { - Áreas de riesgo y } \\
\text { protección }\end{array}$ & $\begin{array}{l}\text { - Restricciones de } \\
\text { uso de suelo }\end{array}$ \\
\hline & & & & & $\begin{array}{l}\text { - Usos condicio- } \\
\text { nados asociados al } \\
\text { tipo de restricción }\end{array}$ \\
\hline
\end{tabular}

Fuente: Elaboración propia. 
Los planes reguladores en cuestión varían bastante según cada contexto, y sobre todo varían considerablemente respecto a la forma en que definen lo que son los riesgos naturales. Esto posee un correlato en el año en que fueron promulgados, por ejemplo el plan de Coquimbo data de 1984 y solo define riesgos solamente a partir de pendientes sobre $40 \%$, mientras que los planes posteriores tienen otros riesgos asociados. Por lo general se definen solamente restricciones de usos de suelo asociados a las áreas expuestas a amenazas naturales, así como también en ciertos casos se da prioridad a la protección de áreas naturales por los servicios ecosistémicos que estas prestan en materia de riesgos. El plan de Antofagasta extiende una mayor cantidad de acciones específicas, sobre todo enfocándose en materia de deslizamientos.

Cabe señalar además que todas las ciudades cuentan con obras de mitigación dispuestas por el Ministerio de Obras Públicas, las cuales varían según cada contexto. Ejemplo de eso podrían ser las defensas fluviales del río Elqui en La Serena o las piscinas de decantación de la quebrada de Macul en Santiago. Además hay planes maestros de evacuación de agua lluvia, o planes de mayor precisión como el de disipación de energía aluvional en Antofagasta ${ }^{7}$.

Los instrumentos de planificación urbana han sido reaccionarios de la experiencia del país en materia de riesgos naturales. Sin duda aún son muy débiles, tanto en relación con la experiencia anterior, y peor aún frente al escenario del cambio climático. Son instrumentos reactivos y poco vinculados a planes de gestión, pero son la base y el resultado de la experiencia de Chile en materia de riesgos naturales. Más que reinventar instrumentos, lo adecuado sería evaluar y mejorar estos, en tanto apuntan en la misma dirección que las directrices del cambio climático en materia de riesgos hidrometeorológicos. A continuación se abordan los contenidos del plan nacional de adaptación al cambio climático, el que si bien no es vinculante, sí da

De todos modos, la ciudad fue sumamente afectada por las Iluvias del año 2015 cuenta de los ejes que se plantean en materia de ciudades y riesgos naturales.

\section{El Plan Nacional de Cambio Climático, la Política de Desarrollo Urbano y riesgos naturales: Nada nuevo bajo el sol}

La versión 2008-2012 del Plan Nacional de Acción de Cambio Climático considera de modo general la idea de riesgo climático, centrándose con mayor fuerza en lo que son los riesgos agrícolas y algunas ideas generales de las implicancias asociadas a la variabilidad climática. En materia de ciudades no enfatizan en la noción de riesgos, pero sí alude a las ciudades costeras en el contexto de los posibles efectos que podría tener sobre ellas el aumento en los niveles del mar, y en menor medida para las ciudades en bordes de cauces naturales (ribereñas). Si bien no considera mayormente los riesgos hidrometeorológicos, las líneas de acción que plantean para las ciudades contiene elementos asociados a los riesgos naturales. Someramente se alude a la planificación urbana, y no se deslizan mayores elementos asociados a riesgos naturales que los ya mencionados. De todos modos, no se plantea una mayor revisión a lo que ya se ha hecho o tiene en materia de riesgos naturales, y se escuda la discusión en los desafíos del cambio climático. Sin duda esto es fundamental, no obstante la falta de revisión a las experiencias previas alarma de que todo cambie para que nada cambie.

En la versión 2014 del Plan Nacional de Adaptación al Cambio Climático se define explícitamente que son los planes reguladores comunales una importante oportunidad para implementar medidas de adaptación. No obstante aparecen los riesgos naturales de manera tangencial dentro de los planes sectoriales, y nuevamente con poca profundización respecto a la experiencia previa. Aparecen los riesgos naturales como algo propio del cambio climático, y como se ha desarrollado en este trabajo, esto no aplica para la realidad nacional. En efecto, se plantea como línea de acción el capacitar a instituciones públicas sobre la adaptación al cambio climático en materia de riesgos naturales, y no se plantea una revisión a los riesgos como tal.

Un símil de esto, que si bien no se enmarca plenamente en la discusión de cambio 
climático, son los Planes Regionales de Ordenamiento Territorial (PROT). Estos planes tienen entre sus elementos centrales la sustentabilidad y los riesgos naturales, los cuales asoman como ejes temáticos del ordenamiento territorial. Ciertamente el ordenamiento territorial es un proceso necesario, y los riesgos naturales al interior de ellos deben ser incorporados. No obstante, nuevamente aparece un nuevo concepto, que alcanza condición de instrumento público indicativo, que soma como novedoso y desplaza todos los avances y experiencias de otros conceptos. Quizás el punto no pase por cambiar la escala del ordenamiento territorial, de comunal en los PRC a regional en los PROT, sino por revisar adecuadamente lo que están haciendo los instrumentos en materia de riesgos naturales. De otro modo, se corre el riesgo de repetir los vicios que ha venido repitiendo la vinculación de los riesgos naturales en los instrumentos de planificación, maquillándolos bajo un nuevo y flamante concepto.

Algo parecido aparece en el marco de la Política de Desarrollo Urbano de 2014 donde, en un contexto nacional de alta vulnerabilidad a riesgos urbanos en al marco del cambio climático, hay poca referencia explícita de cómo la política y las acciones relacionadas buscan reducir esa vulnerabilidad y crear capacidades adaptivas. Es evidencia de la producción de genealogías diferenciadas debido a las disciplinas de los participantes, donde hay poca relación entre las comunidades epistémicas detrás de las políticas, debido a los ministerios mandantes y los investigadores o consultores involucrados. Lo positivo es que hay un reconocimiento de este déficit (PNDU 2014, 14) y medidas a tomar (Objetivo 3.2):

"Hay aspectos no resueltos en la evolución de nuestras ciudades, como la desconexión entre planificación urbana y condiciones mínimas de integración social, la incorporación de los ecosistemas y las cuencas hidrográficas en la planificación, el desarrollo de servicios sanitarios o la falta de herramientas para gestionar los riesgos naturales".

No obstante, de la misma forma que la evolución de las agendas de cambio climático, riesgos y desastre, y planificación del desarrollo urbano han avanzado con comunidades y cumbres separadas, la institucionalidad chilena también representa esa fragmentación. La evidencia de las debilidades de los PRC para anticipar las amenazas de riesgos naturales indica que los esfuerzos para enfrentar los riesgos urbanos de esa naturaleza, con dimensiones climáticas y no climáticas, deben ser integrales y holísticas, pos normales e interdisciplinarios. De la misma forma que el informe SREX del IPCC busca romper los silos de conocimiento y acción, se requieren institucionalidades igual de flexibles y ágiles a nivel nacional para retomar elementos vitales de la planificación urbana previa a la especialización moderna durante el siglo $X X$. Esa planificación de desarrollo urbano fue una planificación donde la anticipación y gestión de riesgos diversos fue la esencia de la planificación.

\section{Conclusión: buscando síntesis para ciudades sustentables}

Michael Hebbert (2014), a través de su énfasis en la historia del estudio de clima urbano y la relevancia de esta para el cambio climático, toca un tema clave para los desafíos centrales de nuestros tiempos. Mientras que hay muchos casos de adaptación urbana y un liderazgo de autoridades locales en la materia, ej. C40, ICLEl (ver Rosenzweig et al., 2011), todavía no hay reconocimiento de la importancia de la formación de comunidades epistémicas en construir discursos, metodologías y lineamientos en paralelo, debido a una lógica moderna y especializada. Debido a la complejidad de los procesos y las interacciones en sistemas socioecológicos, es clave que haya profundidad y detalle relevante para entenderlos mejor. Sin embargo, la fragmentación del conocimiento y la falta de síntesis en sí es una amenaza. Una revisión de la experiencia chilena en términos de planificación urbana y eventos hidrometeorológicos indica que hay mucho trabajo pendiente, en investigación y en política pública e intervenciones específicas.

La evidencia internacional y nacional, y lo planteado en el informe SREX, apunta a un cambio paradigmático en cómo conceptualizar y responder a riesgos urbanos. Sabiendo 
que estos riesgos tienen alta complejidad en términos de temporalidad, especialidad, causalidad y dinámicas socioecológicas panárquicas, la mantención de comunidades epistémicas con sus propias genealogías predicadas sobre disciplinas específicas (ciencia normal), cada uno perfilando lineamientos propios, no resiste análisis. La respuesta es una síntesis y diálogo profundo entre estas comunidades para buscar mensajes comunes que promuevan ciudades resilientes. Estas ciudades resilientes a riesgos urbanos -de índole más natural o más sociocultural- requieren estrategias y planes de acción hechos a la medida de sus propias características. Es por eso que se debe fortalecer la formación de comunidades de conocimiento desde lo local-con científicos y tomadores de decisiones a través de una 'construcción mutua' (Shackley \& Wynne, 1995)- en búsqueda de las medidas apropiadas y no solamente las reglas universales. Estas mismas comunidades epistémicas tendrán las particularidades de cada centro urbano presente en la formulación de respuestas integradas y holísticas. Estas respuestas de anticipación y gestión de riesgos son un lado de la moneda de la planificación urbana (la otra es la promoción de la calidad de vida), y a la vez deben integrar las diversas agendas desarrolladas desde la década de 1970 sobre la planificación del desarrollo urbano, riesgos y desastres, y a la adaptación al cambio climático. En otras palabras, es una agenda de desarrollo urbano sustentable.

\section{Referencias bibliográficas}

ALLMENDINGER, P. Planning Theory. London: Palgrave, 2009.

ARCADIS GEOTÉCNICA. Estudio de riesgos y protección ambiental. - Modificación Plan Regulador Comunal de Antofagasta, 2008.

ARENAS, F.; LAGOS, M. y HIDALGO, $R$. Los riesgos naturales en la planificación territorial. Santiago de Chile: CENTRO DE POLÍTICAS PÚBLICAS, 2010 p.1-11.

BARTON, J.R. Sustentabilidad urbana como planificación estratégica. EURE, 2006, Vol. 32, N 96, p. 27-46.
BARTON, J.R. Climate change adaptation and socio-ecological justice in Chile's Metropolitan Areas: The role of spatial planning instruments. In: BOONE, C. \& FRAGKIAS, M. Urbanization and Sustainability. Linking urban ecology, environmental justice and global environmental change. Nueva York: Springer, 2013 p.137-158.

BECK, U. Risk Society: Towards a new modernity. London: Sage, 1992.

BERMAN, M. All that is solid melts into air: Experience of modernity. Nueva York: Penguin, 1988.

BURTON, I.; HUQ, S.; LIM, B.; PILIFOSOVA, O. \& SCHIPPER, L. From impacts assessment to adaptation priorities: The shaping of adaptation policy. In: SCHIPPER. L \& BURTON, I. The Earthscan reader on Adaptation to Climate Change. London: Earthscan, 2009, p. 377-393.

CONSEIO NACIONAL DE DESARROLLO URBANO (PNDU). Política Nacional de Desarrollo Urbano. Santiago de Chile: Ministerio de Vivienda y Urbanismo, 2014.

EBERT, A.; WELZ, E.; HEINRICHS H.; KRELLENBERG. K. \& HANSJÜRGEN B. Socio- environmental change and flood risks: the case of Santiago de Chile. Erdkunde, 2010, Vol. $64, N^{\circ} 4$, p. 303-313

EDWARDS, P. A Vast Machine: Computer models, climate data and the politics of global warming. Cambridge: MIT, 2009.

FOUCAULT, M. Nietzsche, genealogy, history. In: BOUCHARD, D. Language, CounterMemory, Practice: Selected essays and interviews. Ithaca: Cornell University Press, 1977, p. 139-164.

FOUCAULT, M. The Order of Things: An archaeology of the human sciences. Nueva York: Random House, 1994.

FÜSSEL, H.M. Adaptation planning for climate change: concepts, assessment approaches, and key lessons. Sustainability science, 2007, Vol. 2, No 2, p. $265-275$. 
GARREAUD, R. y RUTLLANT, J. Análisis meteorológico de los aluviones de Antofagasta y Santiago de Chile en el periodo 19911993. Atmósfera, 1996, № 9, p.251-271.

GARreaud, R. Cambio Climático: Bases Físicas e Impactos en Chile. Revista Tierra Adentro, 2011, No 93, p.13-19.

GALLOPIN, G. Sostenibilidad y desarrollo sostenible: Un enfoque sistémico. Santiago de Chile: CEPAL, 2003.

GIDDENS, A. The Politics of Climate Change: National responses to the challenge of global warming. London: Policy Network Paper, 2008.

GUNDERSON, L. \& HOLLING, C.S. Panarchy: Understanding transformations in systems of humans and nature. Washington D.C.: Island Press, 2002.

HEALEY, P. Network complexity and the imaginative power of strategic spatial planning. IN: ALBRECHTS, L. \& MANDEL BAUM, S.J. (editors). The network society: A new context for planning? New York: Routledge, 2005.

HEBBERT, M. Climatology for city planning in historical perspective. Urban Climate, 2014, Vol. 10, № 4, p. 204-215.

HOOD, C. The Art of the State. Oxford: Oxford University Press, 2000.

INTERGOVERNMENTAL PANEL ON CLIMATE CHANGE (IPCC). Cambio climático y biodiversidad. V Informe técnico IPCC, 2002.

INTERGOVERNMENTAL PANEL ON CLIMATE CHANGE (IPCC). Cambio climático 2007: informe de síntesis. Genova: PNUMA y OMM, 2007.

INTERGOVERNMENTAL PANEL ON CLIMATE CHANGE (IPCC). Resumen para responsables de políticas en el Informe especial sobre la gestión de los riesgos de fenómenos meteorológicos extremos y desastres para mejorar la adaptación al cambio climático. Cambridge: Cambridge University Press, 2012.

INTERGOVERNMENTAL PANEL ON CLIMATE CHANGE (IPCC). Glosario (Planton,
S. ed) En Stocker, T. et al. Cambio Climático 2013. Bases físicas. Contribución del Grupo de Trabajo I al Quinto Informe de Evaluación del Grupo Intergubernamental de Expertos sobre el Cambio Climático. Cambridge: Cambridge University Press, 2013.

INTERGOVERNMENTAL PANEL ON CLIMATE CHANGE (IPCC). Informe de Síntesis del Quinto Informe de Evaluación del Grupo Intergubernamental de Expertos sobre el Cambio Climático. Cambridge: Cambridge University Press, 2014.

JACOBS, J. The Death and Life of Great American Cities. New York: Vintage. 1993.

KRATZER, A. Das Stadtklima. Brauvnschweig: F. vieweg ve sohme, 1937.

MARDONES, M. y VIDAL, C. La zonificación y evaluación de los riesgos naturales de tipo geomorfológico: un instrumento para la planificación urbana en la ciudad de Concepción. EURE, 2001, Vol. 27, № 81, p. 97-122.

MARTínEZ ALIER, J. El Ecologismo de los Pobres. Barcelona: Icaria, 2005.

MAX NEEF, M. Foundations of Transdisciplinarity. Ecological Economics, 2005, № 53, p.5-16.

McHALE, M. et al. The new global urban realm: Complex, connected, diffuse, and diverse socio-ecological systems. Sustainability, 2015, Vol. 7, No 5, p. 5211-5240.

MÜLLER, A.; REITER, J. \& WEILAND, U. Assessment of urban vulnerability towards floods using an indicator-based approach - a case study for Santiago de Chile. Natural Hazards and Earth System Sciences, 2011, N ${ }^{\circ}$ 11, p. 2107-2123.

MUMFORD, L. The City in History. New York: Mariner Books, 1968.

NORGAARD, R.B. Development Betrayed: The end of progress and a coevolutionary revisioning of the future. London: Routledge, 1994.

OFICINA NACIONAL DE CAMBIO CLIMÁTICO: Plan nacional de adaptación al 
cambio climático. Santiago de Chile: Min. Medio Ambiente, 2014.

ONU. United Nations Framework Convention on Climate Change (UNFCCC). Rio de Janeiro: 1992.

ROMERO, H. y MENDOÇA, M. Análisis comparativo de los factores naturales y urbanos de las inundaciones ocurridas en las ciudades costeras de Valparaíso y Florianópolis. Cuaderno de Investigación Urbanística, 2009, No 66, p.96-107.

ROMERO, H.; MOLINA, M.; MOSCOSO, C. \& SARRICOLEA, P. Climate change and urban sustainability of Chilean metropolitan cities. En: DA SILVA, P.; COSTA, W.; SANT'ANNA, J. \& ZULLO, J. Public policy, mitigation and adaptation to climate change in South America. Sao Paulo: Instituto de Estudos Avacados da Universidad de Sao Paulo, 2009, p.221-227.

PELLING, M. Adaptation to climate change: From resilience to transformation. London: Routledge, 2011.

POHL, C. What is progress in transdisciplinary research. Futures, 2011, No 43, p. 618-626.

PUGLISI, C. \& INDIRLI, M. Geomorphologic hazard in the city of Valparaiso. MAR VASTO Project Technical Report. Washington D.C.: InterAmerican Development Bank (IDB), 2008.

ROSENZWEIG, C.; SOLECKI, W.D.; HAMMER, S.A. \& MEHROTRA, S. (editors). Climate Change and Cities (First Assessment Report of the Urban Climate Change Research Network). Cambridge: Cambridge University Press, 2011.

SARRICOLEA, P. Niveles de vulnerabilidad a amenazas naturales en una ciudad intermedia y sus áreas de expansión. El caso de La Serena IV región de Coquimbo. Santiago de Chile: Memoria para optar al título de Geógrafo, Facultad de Arquitectura y Urbanismo, Universidad de Chile, 2004.

SCHIPPER, L. \& BURTON, I. Understanding Adaptation: Origins, Concepts and Poli- cy. In: SCHIPPER, L \& BURTON, I. The Earthscan reader on Adaptation to Climate Change. London: Earthscan, 2009, p.1-10.

SCHIPPER, L. \& BURTON, T. Disaster risk, climate change and international development: scope for, and challenges to integration Disasters, 2011, Vol. 30, № 1, p.19- 38.

SEPÚLVEDA, S.; REBOLLEDO, S. \& VARGAS, G. Recent catastrophic debris flows in Chile: Geological hazard, climatic relationships and human response. Quaternary International, 2006, No 158, p.83-95.

SHACKLEY, S. \& WYNNE, B. Global climate change: The mutual construction of an emergent science-policy domain. Science and Public Policy, 1995, Vol. 22, No 4, p.218-230.

SMITHERS, J. \& SMIT, B. Human adaptation to climatic variability and change. In: SCHIPPER, L. \& BURTON, I. The Earthscan reader on Adaptation to Climate Change. London: Earthscan, 2009, p.15-33.

STAPPUNG, C. Lluvias de diseño de sistemas de aguas Iluvias en Chile. In: XIV Congreso de la Sociedad Chilena de Ingeniería Hidráulica, Santiago de Chile, 1999.

STORJBJÖK, S. Governing Climate Adaptation in the Local Arena: Challenges of Risk Management and Planning in Sweden. Local Environment: The International Journal of Justice and Sustainability, 2007, Vol. 12, No 5, p.457-469.

UNIVERSIDAD DE CHILE (DGF). Estudio de la variabilidad climática en Chile para el siglo XXI. Santiago de Chile: CONAMA/Universidad de Chile, 2006.

VARGAS, G.; ORTLIEB, L. y RUTLLANT, J. Aluviones históricos en Antofagasta y su relación con eventos El Niño/ Oscilación del Sur. Revista Geológica de Chile, 2000, Vol. 27, No 2, p.157-175.

WHITE, G. Human Adjustment to Floods: A geographical approach to the flood problem in the United States. Chicago: University of Chicago, 1945. 
WILLOWS, R. \& CONNEL, R. climate adaptation: Risk, uncertainty and decision making. London: UKCIP Technical Report. Uk Climate Impacts Programme, 2003.

WILSON, E. Adapting to Climate Change at the Local Level: The Spatial Planning Response. Local Environment: The International Journal of Justice and Sustainability, 2007, Vol. 11, No 6, p. 609-625.

WISNER, B.; BLAIKIE, P.; CANNON, T. \& DAVIS, I. At Risk: natural hazards, people`s vulnerability and disasters. London: Routledge, 2003

WYNNE, B. Strange Weather Again: Climate science as political art. Theory, Culture, Society, 2010, Vol. 27, No 2, p.289-305.

YOUNGBLOOD, D. Interdisciplinary Studies and the bridging disciplines: A matter of process. Journal of Research Practice, 2007, Vol. 3, No 2, p.1-8. 